\title{
A mixed-method systematic review of text-based telehealth interventions in eating disorder management
}

Text-based telehealth in $\mathrm{ED}$

management

Xiaoyun Zhou

Centre for Online Health, Princess Alexandra Hospital, Woolloongabba, Australia and

The University of Queensland, Brisbane, Australia

Matthew Bambling

Navitas ACAP School of Psychology, Brisbane, Australia; Centre for Online Health, Princess Alexandra Hospital, Woolloongabba, Australia;

The University of Queensland, Brisbane, Australia and

School of Psychology, Queensland University of Technology, Brisbane, Australia, and

Sisira Edirippulige

Centre for Online Health, Princess Alexandra Hospital,

Woolloongabba, Australia and

The University of Queensland, Brisbane, Australia

\begin{abstract}
Purpose - Eating disorders (EDs) is a major health condition affecting $9 \%$ of the global population and $10 \%$ of those with EDs lost their lives as a result. Text-based telehealth interventions (TTIs) seem to provide a low-cost and convenient treatment option; however, the evidence is scarce. This study aimed to synthesize evidence relating to the use of TTIs for the management of EDs.

Design/methodology/approach - Five databases were searched published between January 2020 and May 2019. The authors used keywords relating to telehealth and EDs. The authors used Joanna Briggs Institute's (JBI's) critical appraisal instrument to assess the methodology quality of included studies.

Findings - Fifteen studies were included in this mix-method systematic review and assessed for methodology quality. Email, web-based texting, text-messaging and online chat room were used as mode for deliver healthcare for patients with EDs. In the treatment phase, all studies (nine studies; $n=860$ participants) showed effectiveness (for RCTs) and usefulness (for non-RCT studies). In the aftercare phase (six studies; $n=364$ participants), the results regarding the effectiveness of TTIs were mixed. Two studies showed effectiveness whilst four studies did not find statistically significant change of ED outcomes.

Research limitations/implications - The qualities of these studies varied; firstly, $66 \%(n=10)$ of the studies were non-randomized studies (e.g. single-arm trial, case report) with small samples. Moreover, onefourth $(n=4)$ of the studies did not use validated instruments or indicate the instrument. Also, half $(n=7)$ of the studies used TTIs as adjunct to face-to-face treatment or bigger online treatment, it is hard to make conclusion that the changes were due to TTIs' effect. In addition, follow-up rate is not satisfactory, thus results should be interpreted cautiously.
\end{abstract}

(C) Xiaoyun Zhou, Matthew Bambling and Sisira Edirippulige. Published in Journal of Health Research. Published by Emerald Publishing Limited. This article is published under the Creative Commons Attribution (CCBY 4.0) licence. Anyone may reproduce, distribute, translate and create derivative works of this article (for both commercial and non-commercial purposes), subject to full attribution to the original publication and authors. The full terms of this licence may be seen at http://creativecommons. org/licences/by/4.0/legalcode

Funding: There is no funding for this research.

Received 24 March 2021 Revised 7 June 2021 17 June 2021

Accepted 14 July 2021 
JHR

36,6

Practical implications - TTIs seem to be promising for management of EDs, particularly in the treatment phase. This provides an important treatment option for health practitioners and people with EDs as an alternative or in adjunct with face-to-face services.

Originality/value - This is the first review to synthesis the use of TTIs for ED management.

Keywords Telehealth, Telemedicine, Text-based, Eating disorders

Paper type Review

\section{0}

\section{Introduction}

Eating disorders (EDs) include a range of health issues characterized by a persistent disturbance of eating or eating-related behaviors resulting in the altered consumption or absorption of food [1]. Globally, this is a major health problem that requires high utilization of health services and medical attention. Worldwide, $8.4 \%$ of women and $2.2 \%$ of men were diagnosed with EDs in 2019 [2, 3]. The use of healthcare services by the people with EDs is comparatively high $[1,4,5]$. Annual costs per ED patient in 2012 ranged from 1,288 to 8,042 US\$ 2008 purchasing power parities [6].

EDs significantly impair patients' daily functioning and quality of life. They are linked with cardiovascular disease, neurological symptoms and disruptions to the gastrointestinal system $[7,8]$. EDs are also strongly associated with mental health issues, such as anxiety, depression, self-harm, substance abuse and personality disorders [2, 7, 9]. ED patients often show significant social isolation, poor quality of life, poor academic performance and higher rates of substance abuse. Recovery rates for those who receive treatments for EDs are reportedly low, and the relapse rates are high [10-12]. Approximately $30 \%$ of patients with bulimia nervosa $(\mathrm{BN})$ and eating disorder not otherwise specified (EDNOS) remain ill for 10 to 20 years following the initial presentation (15). Mortality rates for individuals with EDs are about twice as high as people without Eds [13].

Despite the severity and negative impact of EDs, up to $45 \%$ of individuals with EDs never receive treatment for their eating-related problems [14]. Some of the main reasons that ED patients do not to seek treatments include the lack of knowledge about available health services $[15,16]$, high cost of treatment $[15,17]$ and stigma $[15,16]$ associated with EDs. Specialist services for EDs are generally available at tertiary hospitals. Lack of access is the main barrier to seeking treatment for patients living in rural and remote areas [18].

Telemedicine has been effectively used to provide healthcare services to people with Eds [19-22]. It has also been successfully used to assess, treat and monitor people with Eds [20, 22-24]. Telemedicine is the use of information and communication technologies (ICTs) for delivering healthcare at a distance. It includes telephone counseling, video consultations and remote monitoring. Previous studies found that the use of video-consultation for providing treatment to patients with BN had similar outcomes to face-to-face consultations [17, 25-27]. A systematic review also suggested that videoconferencing is a promising approach to treat EDs [28]. Videoconferencing for counseling sessions is accepted by both patients and medical professionals [29]. The advantages of videoconferencing include that people feel more control over the verbal interactions and less intimidated compared to face-to-face sessions [30]. However, the disadvantages of videoconferencing include scheduling constraints, compromised anonymity [31] and the need for patients to have sophisticated computer equipment and network capacity [32].

Text-based online communication is gaining popularity over the last decade globally. In 2017, over 4.2 billion people texted worldwide, sending out 15 million texts every minute of each day [33]. In response, healthcare facilities have explored the use of text-based communications to deliver healthcare (i.e. text-based telehealth interventions, abbreviated as TTIs) [34]. Evidence for the effectiveness of TTIs in various health disciplines is rapidly 
growing [35-37]. For example, TTIs have shown promising results in management of diabetes [38], smoking cessation [39], obesity [40], as well as for mental health problems (e.g. anxiety, depression and EDs) [35, 36, 41].

Previous research examined the use of text-based telemedicine techniques for providing healthcare services to patients with EDs. However, to our knowledge, no review has attempted to appraise the evidence for the utility of TTIs, techniques and technologies used and the impact of TTIs on patient outcomes. In order to expand knowledge of these topics, we conducted a review of qualitative and quantitative studies to synthesize the evidence on the use of TTIs.
Text-based telehealth in $\mathrm{ED}$

management

1151

\section{Methods \\ Search procedures}

We conducted a literature search using the keywords related to EDs and text-based telemedicine in five electronic databases, including PsycINFO, PubMed, Embase, Cochrane Library and ProQuest, with the assistance of an experienced library consultant $(\mathrm{JH})$. We used this combination of search terms: (telemedicine OR mHealth OR "mobile health" OR "text message" OR text-messaging OR text-messages OR textbased OR email OR e-mail OR chatroom OR "chat room" OR forum OR "discussion board" OR "message board”) AND ("eating disorder" OR "eating disorders" OR bulimi* OR anorexi* OR binge eat* OR EDNOS) (Appendix 1). Additional hand searches with reference lists were also performed. Reviewed papers included the research papers published between January 2000 and May 2021.

The inclusion and exclusion criteria for reviewed papers were formulated using the following PICO statement: (1) Population: participants have ED-related symptoms or are formally diagnosed with EDs, including anorexia nervosa (AN), BN, binge-eating disorder (BED) and EDNOS. Thus, preventive programs were excluded; (2) Intervention: therapy related communication between therapist and patient used text-based telemedicine techniques. Interventions that were delivered by videoconferencing and phone were excluded. Studies examining self-help interventions were excluded; (3) Comparison: randomized controlled studies assessing the effectiveness of text based telemedicine interventions in EDs were included. Since evidence relating to text-based telemedicine interventions on EDs were relatively limited, single arm trials and qualitative studies were also included. (4) Outcomes: studies reporting ED-related outcomes related to text-based telemedicine techniques were included. We screened the selected articles against inclusion and exclusion criteria according to the PRISMA checklist [42].

\section{Data extraction}

In addition to basic demographic details of the research articles (ex: author, year, country and study design), two independent researchers (XZ\&SE) collected and tabulated information about the type of TTI, disease area, type of therapy and outcomes.

\section{Assessment of methodological quality}

Qualitative studies were assessed by using Joanna Briggs Institute's (JBI) critical appraisal instrument for qualitative research [43]. Quantitative studies were assessed by using the JBI's critical appraisal instrument for RCTs and non-randomized experimental studies [44, 45]. Two reviewers (XZ and SE) conducted the assessment independently. Discrepancies were resolved by the involvement of a third reviewer $(\mathrm{MB})$. For randomized controlled trials, studies meeting at least ten out of thirteen criteria were categorized into "good" quality, seven to nine were categorized into "moderate" quality, less than seven were deemed "poor" quality. 
For quasi-experimental studies, studies meeting at least seven out of nine criteria were categorized into "good" quality, five to seven criteria were "moderate" quality, less than five were "poor". For qualitative studies, studies meeting eight out of ten criteria were deemed "good" quality, five to seven were "moderate" quality, and less than five were categorized into "poor" quality.

\section{Results}

The initial search resulted in 653 articles. After duplicate records were removed, 341 articles remained for review. After screening titles and abstracts, we excluded 270 articles (Figure 1).

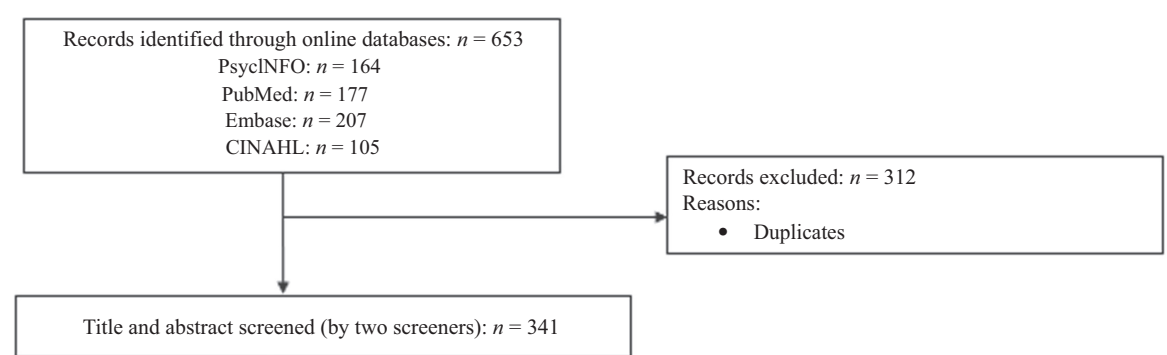

Figure 1.

PRISMA flow chart for study inclusion

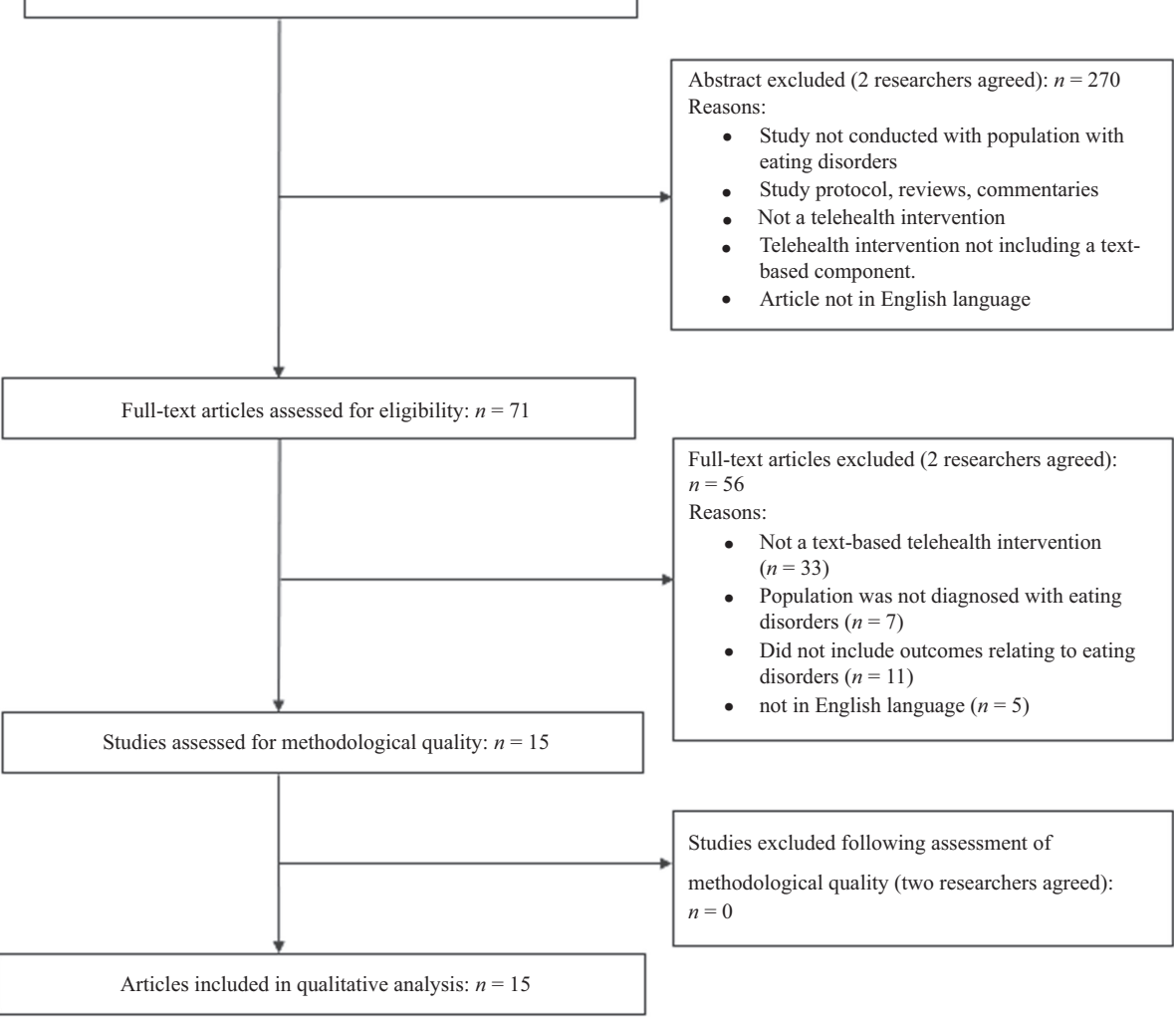


We reviewed 71 full text articles using the inclusion and exclusion criteria. We removed 56 ineligible articles. Thus, fifteen research papers were reviewed in this study.

\section{Characteristics of included papers}

Table 1 shows the key features of all 15 articles, including author, year, country, study design, TTIs medium, TTIs use, diagnosis, treatment phase, sample size and result. All articles were published between 2001 and 2017: 47\% $(n=7)$ were published between 2001 and 2010 and $53 \%(n=8)$ published after 2011. As for countries where the study was conducted, $33 \%$ $(n=5)$ were in Germany, 33\% $(n=5)$ in USA, $20 \%(n=3)$ in UK, $7 \%(n=1)$ in Hungary and $7 \%(n=1)$ in Netherlands. Regarding the types of EDs studied, $47 \%(n=7)$ of articles discussed a single subtype of EDs and the other 8 articles $(53 \%)$ discussed a combination of subtypes of EDs. Thirty-three percent $(n=5)$ were randomized controlled studies (RCTs); $40 \%(n=6)$ were single-arm trials; $13 \%(n=2)$ were case reports; $7 \%(n=1)$ descriptive studies, and $7 \%(n=1)$ had a single-case alternating treatment design. Studies used four different text-based telemedicine methods: Email ( $40 \% ; n=6)$, text-messaging $(33 \% ; n=5)$, webpage $(7 \% ; n=2)$ and online chat $(7 \% ; n=2)$. Nine studies $(60 \%)$ used TTIs as a standalone intervention, whilst $6(40 \%)$ used TTIs as an adjunct. TTIs were used to manage EDs at different stages: Nine studies (60\%) occurred during treatment for EDs, and six studies (40\%) were conducted during aftercare.

\section{TTIs during treatment}

During treatment period, text-based telehealth techniques included email, web-based texting, text-messaging and online chat rooms. The psychological theories underpinning these interventions were cognitive behavioral techniques (CBT) and motivational interviewing techniques (MI). CBT used in TTIs included keeping a food diary, psychoeducation, eating regular meals, as well as modifying negative automatic thoughts, emotional regulation and maladaptive behaviors were used in TTIs (Table 2). Researchers also sent motivational messages via messaging apps.

All nine studies (a total of 860 participants) showed effectiveness (for RCTs) and usefulness (for quasi-experimental studies and qualitative studies) of TTIs among individuals with EDs. Robinson and Serfaty [46] tested the effectiveness of using email to reduce ED-related symptoms among patients with BN, BED and EDNOS. This study found email-delivered intervention was effective both at the end of the intervention and at 3-month follow up. Wagner et al. [47] found that an online asynchronous chat on a webpage with patients with BED was effective in reducing binge-eating episodes, depression level, as well was promoting recovery. Zerwas et al. [48] conducted an intervention in which patients with BN received psychotherapy from therapists. This study found that the text-based telemedicine intervention was equivalent to face-to-face psychotherapies in increasing abstinence rate at follow up. The intervention also alleviated binge eating and depression and improving quality of life at both end of treatment and follow-up. Robinson and Serfaty [49] tested the effectiveness of email therapy on participants with BN, BED and EDNOS. Results indicated that email therapy was effective in reducing bulimic and relevant depressive symptoms. ter Huurne et al. [50] tested the effectiveness of a web-based program in which participants with BN and related EDNOS communicated with therapists via text asynchronously. Results indicated that the intervention was effective in reducing BN-relevant symptoms and improving body satisfaction, quality of life, and general mental and physical health. The improvements sustained after 6 months. Shingleton et al. [51] tested effectiveness of text-messaging in reducing AN and BN. This study found that the intervention was effective in improving motivation among normal weight individuals. Yager $[52,53]$ reported the use of email with patients diagnosed with AN was
Text-based telehealth in $\mathrm{ED}$

management

1153 
JHR
36,6

Table 1.

Characteristics of studies included in mixed methods systematic review of text-based telehealth interventions in eating disorder management, January 2000-

May 2021

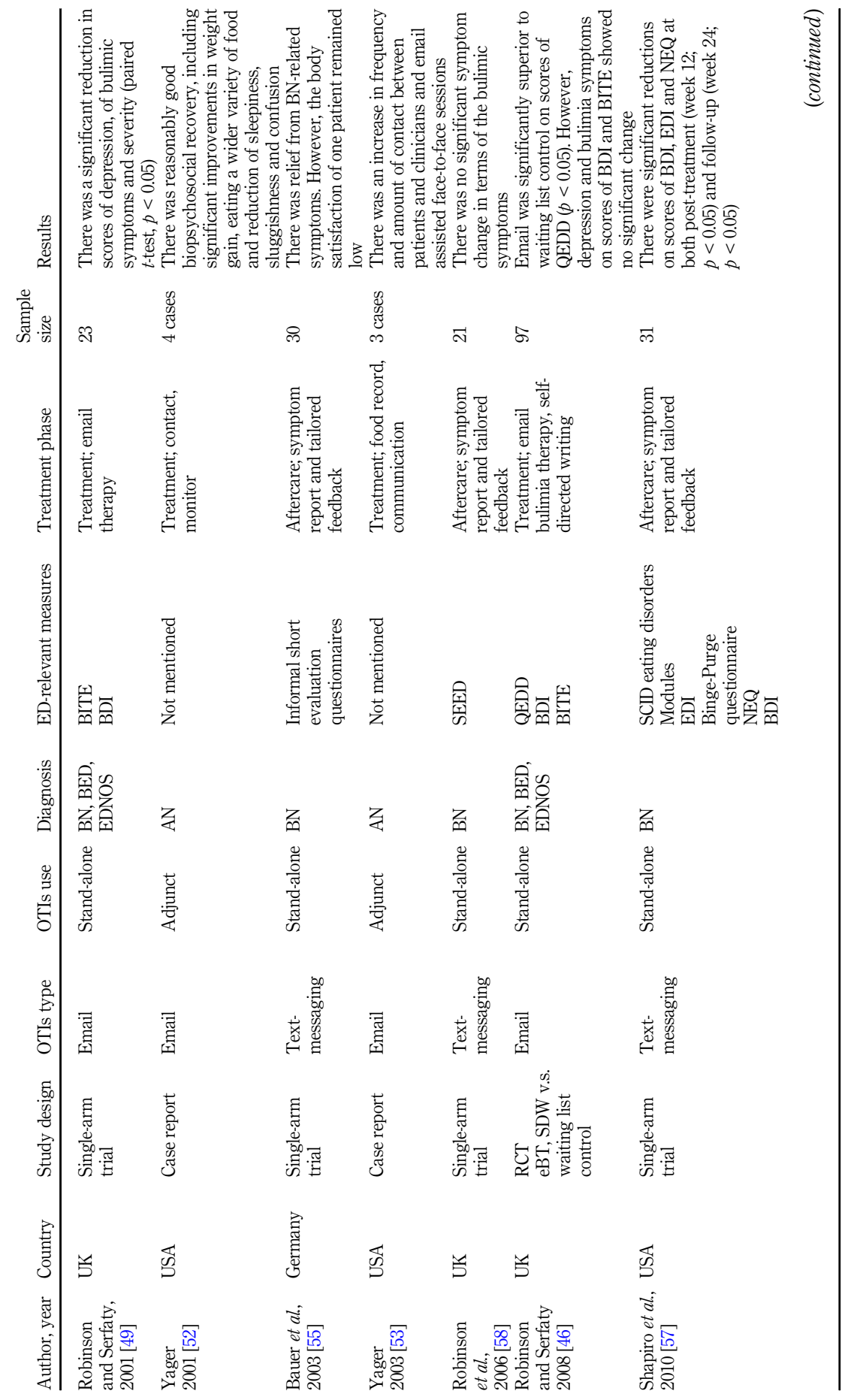




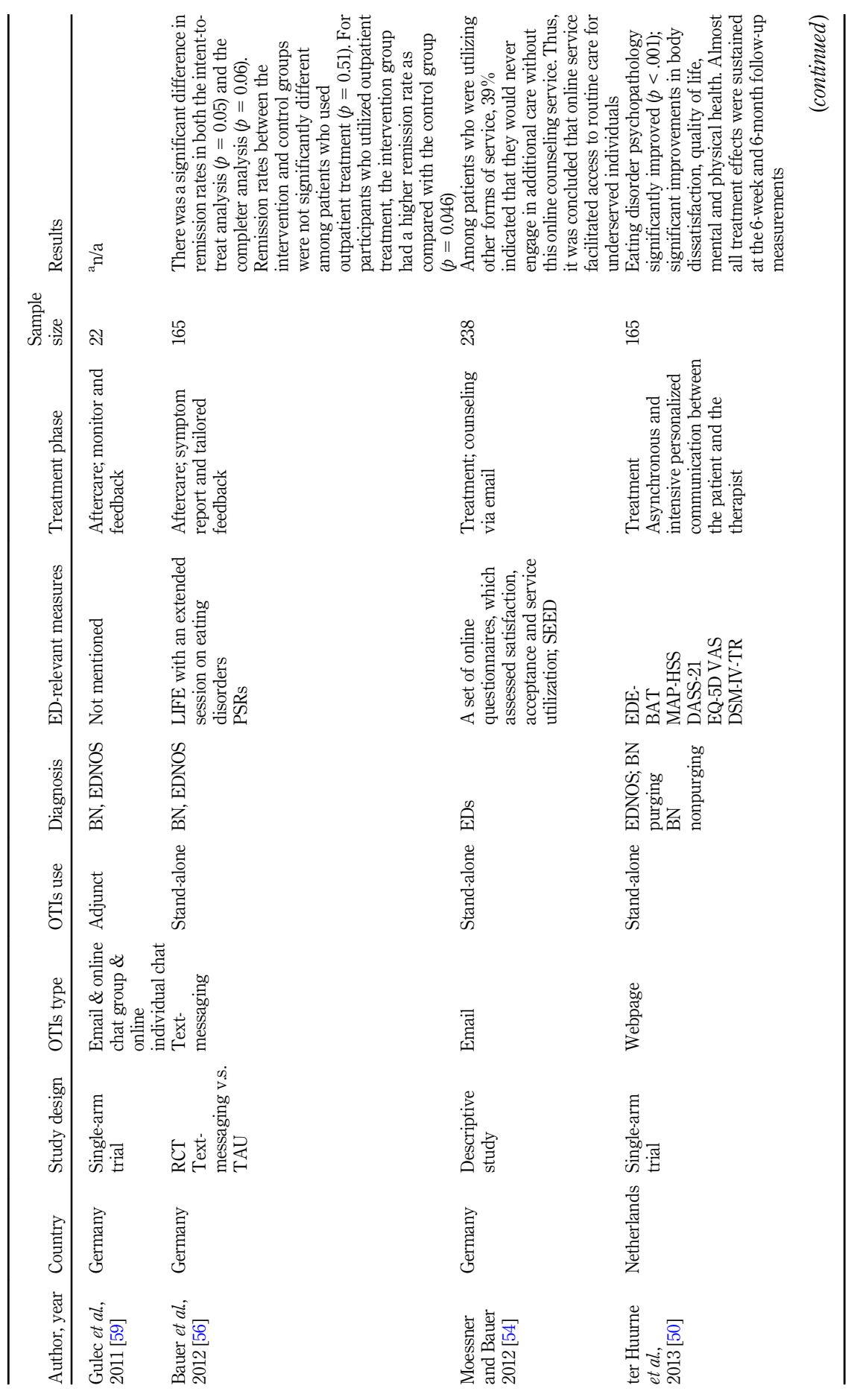

Text-based telehealth in ED management

1155

Table 1. 
JHR
36,6

1156
Table 1.

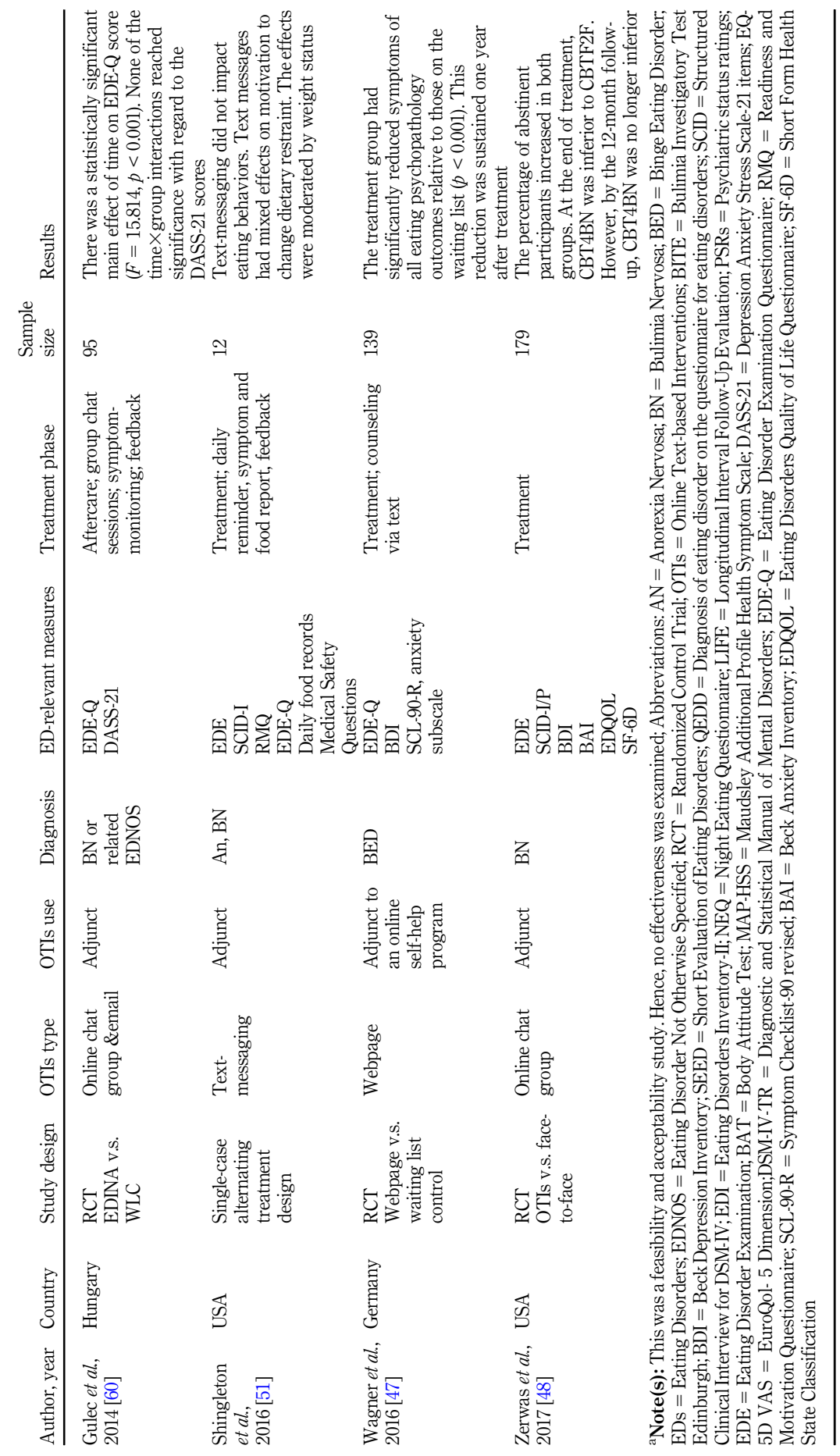


Treatment

(1) Deliver cognitive behavioral therapies for participants

(2) Monitor symptoms relating to eating disorders

(3) Deliver motivational interviewing (MI)

(4) Send motivational messages to participants

(5) Participants report eating disorderrelated symptoms

(6) Clients do "homework" and send it back to the researcher

(7) Provide feedback to participants about their progress

(8) Set goal and/or plan

(9) Psycho-education

(10) Deliver self-control techniques

(11) Deliver exposure techniques
Aftercare

(1) Monitor eating disorder symptoms

(2) report positive or negative life events, thoughts, feelings and their progress (or lack of progress)

(3) Automatic personalized feedback to educate the recipients about positive and negative changes in their status. The feedback aims to motivate participants to solve their own problems

(4) Send feedback about the participants' progress

(5) Online counseling

Examples of Online

Text-based

Interventions (OTIs) used in the treatment phase and aftercare phase for eating disorders in mixed methods systematic review

useful tool for communication in combination with face-to-face sessions and improved recovery among this population. Moessner and Bauer [54] reported that email as a stand-alone intervention facilitated access to routine care for underserved individuals.

\section{TTIs during aftercare stage}

Six studies (a total of 364 participants) used TTIs to provide aftercare for participants to prevent relapse. During aftercare, TTIs were used mainly for monitoring patients. In our review, we found that phones were mainly used text-messaging (in four studies) and a combination of online chat and email (in two studies). Researchers used TTIs to monitor the change of ED-related symptoms, thoughts and emotions as well as to provide feedback. When necessary, TTIs were also used to deliver online counseling (see Table 2). The results regarding the effectiveness of TTIs were mixed. Three studies [55-57] used text-messaging to monitor changes in ED-related symptoms and provide tailored feedback. Their results indicated a reduction in ED-related symptoms after intervention. In contrast, a similar intervention [58] did not find statistically significant changes. Two studies [59, 60] used an online chat group and email to provide aftercare support for ED patients. This study found that this intervention was acceptable and feasible, but not effective.

\section{Methodological quality of included studies}

For randomized controlled trials (Table 3), we found that the quality of evidence for three studies were "good" and two were "moderate." For quasi-experimental studies (Table 4), quality assessment showed that five studies were categorized into "good" quality, while two were "moderate." Because six out of seven quasi-experimental studies were single-arm trial, none of them had control group. For qualitative studies (Table 5), all three studies were of "good" quality.

\section{Discussion}

We found evidence suggesting that telemedicine is effective in treating Eds [20, 26]. For example, video-based modality (i.e. videoconferencing) produced an equivalent outcome to face-to-face conditions [17, 27]. Online CBT as well as Internet-based self-help programs 


\begin{tabular}{|c|c|c|c|c|c|c|}
\hline $\begin{array}{l}\text { JHR } \\
36,6\end{array}$ & Citation & $\begin{array}{l}\text { Wagner et al. } \\
\text { (2016) [47] }\end{array}$ & $\begin{array}{l}\text { Zerwas et al. } \\
\text { (2017) [48] }\end{array}$ & $\begin{array}{l}\text { Bauer et al. } \\
\text { (2012) [56] }\end{array}$ & $\begin{array}{l}\text { Robinson et al. } \\
\text { (2008) [46] }\end{array}$ & $\begin{array}{l}\text { Gulec et al. } \\
\text { (2014) [60] }\end{array}$ \\
\hline \multirow[b]{3}{*}{1158} & Randomization & Y & $\mathrm{Y}$ & $\mathrm{U}$ & Y & $\mathrm{U}$ \\
\hline & $\begin{array}{l}\text { Allocation } \\
\text { concealment }\end{array}$ & $\mathrm{Y}$ & $\mathrm{Y}$ & $\mathrm{U}$ & $\mathrm{U}$ & $\mathrm{U}$ \\
\hline & $\begin{array}{l}\text { Groups similar at } \\
\text { baseline }\end{array}$ & $\mathrm{Y}$ & $\mathrm{Y}$ & $\mathrm{U}$ & $\mathrm{Y}$ & $\mathrm{U}$ \\
\hline \multirow{12}{*}{$\begin{array}{l}\text { Table } 3 \text {. } \\
\text { Critical appraisal } \\
\text { results of eligible } \\
\text { randomized controlled } \\
\text { trials in systematic } \\
\text { review of online text- } \\
\text { based intervention and } \\
\text { eating disorder } \\
\text { management }\end{array}$} & Blinding: Participants & $\mathrm{N}$ & $\mathrm{N}$ & $\mathrm{U}$ & $\mathrm{N}$ & $\mathrm{U}$ \\
\hline & Blinding: delivery & $\mathrm{N}$ & $\mathrm{N}$ & Y & $\mathrm{U}$ & $\mathrm{U}$ \\
\hline & $\begin{array}{l}\text { Blinding: outcome } \\
\text { assessment }\end{array}$ & $\mathrm{N}$ & $\mathrm{Y}$ & $\mathrm{Y}$ & $\mathrm{Y}$ & $\mathrm{Y}$ \\
\hline & $\begin{array}{l}\text { Groups treated } \\
\text { identically }\end{array}$ & $\mathrm{Y}$ & $\mathrm{Y}$ & Y & $\mathrm{Y}$ & $\mathrm{Y}$ \\
\hline & Follow-up complete & $\mathrm{Y}$ & $\mathrm{Y}$ & $\mathrm{Y}$ & $\mathrm{Y}$ & $\mathrm{Y}$ \\
\hline & Analysis according to & $\mathrm{Y}$ & $\mathrm{Y}$ & $\mathrm{Y}$ & $\mathrm{Y}$ & $\mathrm{U}$ \\
\hline & Same outcome & $\mathrm{Y}$ & $\mathrm{Y}$ & $\mathrm{Y}$ & $\mathrm{Y}$ & $\mathrm{Y}$ \\
\hline & Outcome is reliable & $\mathrm{Y}$ & $\mathrm{Y}$ & Y & Y & $\mathrm{Y}$ \\
\hline & Appropriate statistical & $\mathrm{Y}$ & $\mathrm{Y}$ & $\mathrm{Y}$ & $\mathrm{Y}$ & $\mathrm{Y}$ \\
\hline & Trial design is & $\mathrm{Y}$ & $\mathrm{Y}$ & $\mathrm{Y}$ & Y & $\mathrm{Y}$ \\
\hline & $\begin{array}{l}\text { appropriate } \\
\text { Final analysis }\end{array}$ & Good & Good & Moderate & Good & Moderate \\
\hline & \multicolumn{6}{|c|}{ Note(s): Abbreviations: $\mathrm{Y}=\mathrm{Yes} ; \mathrm{N}=\mathrm{No} ; \mathrm{U}=$ Unclear } \\
\hline
\end{tabular}

reduced ED-related symptoms more effectively than the waiting list control group [61, 62]. Our current review found the evidence that TTIs have positive effects on managing EDs. Thus, this analysis adds new evidence showing effectiveness of telemedicine for Eds [63].

Among studies testing the effectiveness and usefulness in treating BN, BED and EDNOS, all studies showed that TTIs were effective in reducing bulimic symptoms and severity. We found that TTIs which were underpinned by CBT and were particularly effective in interventions. This finding is consistent with previous evidence on the effectiveness of CBT on EDs [64]. Another technique used in the included studies was motivational interviewing (MI). It was found that text-messaging underpinned by MI techniques had effect on motivation to change rather than on eating behaviors [51].

In the aftercare stage, previous studies have shown that outpatient care prevents relapse after acute care. In addition, mobile and internet-based interventions were promising and may help maintain treatment gains [65]. Our current study showed that text-based interventions were helpful during the aftercare phase because they enabled monitoring of patients' symptoms in a less disruptive way for patients. When the text-based feedback is tailored to the reported symptoms, patients may want to maintain behavior changes. However, some participants provided feedback that TTIs may not be able to provide the empathetic feedback which human therapists are able to. Therefore, future studies may explore ways to improve the patients' experience.

Current studies also found various features, as well as advantages and disadvantages of different modalities of TTIs. Interventions delivered via text messages were preprogrammed in reviewed studies. These interventions usually served a single purpose such as symptom monitoring [57]. Others focused on global health and increasing motivation to change eating behaviors [51]. Previous studies also reported that the purpose of the text messaging was to provide support and assist in self-monitoring. They distributed supportive messages and self-monitoring procedures in mental health interventions [66]. Therefore, text messaging 


\begin{tabular}{|c|c|c|c|c|c|c|c|c|}
\hline Citation & $\begin{array}{l}\text { Robinson } \\
\text { et al. }(2006) \\
{[58]}\end{array}$ & $\begin{array}{l}\text { Shapiro } \\
\text { et al. } \\
(2010)[57]\end{array}$ & $\begin{array}{l}\text { Gulec } \\
\text { et al. } \\
\text { (2011) } \\
{[59]}\end{array}$ & $\begin{array}{l}\text { ter } \\
\text { Huurne } \\
\text { et al. } \\
\text { (2013) } \\
{[50]} \\
\end{array}$ & $\begin{array}{l}\text { Bauer } \\
\text { et al. } \\
\text { (2003) [55] }\end{array}$ & $\begin{array}{l}\text { Robinson } \\
\text { and Serfaty } \\
(2001) \text { [49] }\end{array}$ & $\begin{array}{l}\text { Shingleton } \\
\text { et al. }(2016) \\
{[51]}\end{array}$ & $\begin{array}{r}\text { Text-based } \\
\text { telehealth in } \\
\text { ED } \\
\text { management }\end{array}$ \\
\hline $\begin{array}{l}\text { Clear } \\
\text { definition of }\end{array}$ & $\mathrm{Y}$ & Y & Y & $\mathrm{Y}$ & $\mathrm{Y}$ & \multirow[t]{2}{*}{$\mathrm{Y}$} & Y & 1159 \\
\hline "effect" & & & & & & & & \\
\hline $\begin{array}{l}\text { Participants } \\
\text { are similar }\end{array}$ & $\mathrm{Y}$ & NA & $\mathrm{U}$ & $\mathrm{N}$ & $\mathrm{U}$ & $\mathrm{Y}$ & Y & \\
\hline $\begin{array}{l}\text { Participants } \\
\text { receive similar } \\
\text { treatment }\end{array}$ & NA & NA & $\mathrm{Y}$ & $\mathrm{Y}$ & $\mathrm{Y}$ & $\mathrm{Y}$ & Y & \\
\hline Control group & $\mathrm{N}$ & $\mathrm{N}$ & $\mathrm{N}$ & $\mathrm{N}$ & $\mathrm{N}$ & $\mathrm{N}$ & $\mathrm{Y}$ & \\
\hline $\begin{array}{l}\text { Multiple } \\
\text { measures }\end{array}$ & $\mathrm{Y}$ & Y & $\mathrm{Y}$ & $\mathrm{Y}$ & $\mathrm{Y}$ & Y & Y & \\
\hline $\begin{array}{l}\text { Complete } \\
\text { follow-up }\end{array}$ & $\mathrm{Y}$ & $\mathrm{U}$ & $\mathrm{Y}$ & $\mathrm{Y}$ & $\mathrm{Y}$ & $\mathrm{Y}$ & Y & \\
\hline $\begin{array}{l}\text { Outcomes } \\
\text { measured in a } \\
\text { similar way }\end{array}$ & $\mathrm{Y}$ & $\mathrm{Y}$ & $\mathrm{Y}$ & $\mathrm{Y}$ & $\mathrm{Y}$ & Y & Y & $\begin{array}{r}\text { Table } 4 . \\
\text { Critical appraisal }\end{array}$ \\
\hline $\begin{array}{l}\text { Outcomes } \\
\text { measured in a } \\
\text { reliable way }\end{array}$ & Y & Y & $\mathrm{Y}$ & $\mathrm{Y}$ & $\mathrm{Y}$ & $\mathrm{Y}$ & Y & $\begin{array}{l}\text { results of eligible quasi- } \\
\text { experimental studies } \\
\text { (non-randomized }\end{array}$ \\
\hline $\begin{array}{l}\text { Appropriate } \\
\text { statistical } \\
\text { analysis }\end{array}$ & $\mathrm{Y}$ & $\mathrm{Y}$ & $\mathrm{Y}$ & $\mathrm{Y}$ & $\mathrm{U}$ & $\mathrm{Y}$ & Y & $\begin{array}{l}\text { experimental studies) } \\
\text { trials in systematic } \\
\text { review of online text- }\end{array}$ \\
\hline Total & Good & Moderate & Good & Good & Moderate & Good & Good & $\begin{array}{r}\text { based intervention and } \\
\text { eating disorder }\end{array}$ \\
\hline \multicolumn{8}{|c|}{ Note(s): Abbreviations: $\mathrm{Y}=$ Yes; $\mathrm{N}=$ No; $\mathrm{NA}=$ Not Applicable; $\mathrm{U}=$ Unclear } & management \\
\hline \multicolumn{4}{|l|}{ Citation } & $\begin{array}{l}\text { Yager (2001) } \\
{[52]}\end{array}$ & $\begin{array}{l}\text { Yager (2003) } \\
{[53]}\end{array}$ & \multicolumn{2}{|c|}{$\begin{array}{l}\text { Moessner et al. (2012) } \\
{[54]}\end{array}$} & \\
\hline \multicolumn{4}{|c|}{$\begin{array}{l}\text { Congruity between philosophical perspective and } \\
\text { methodology }\end{array}$} & Y & $\mathrm{Y}$ & $\mathrm{Y}$ & & \\
\hline \multicolumn{4}{|c|}{ Congruity between methodology and question } & $\mathrm{Y}$ & Y & $\mathrm{Y}$ & & \\
\hline \multicolumn{4}{|c|}{$\begin{array}{l}\text { Congruity between methodology and data } \\
\text { collection }\end{array}$} & $\mathrm{Y}$ & $\mathrm{Y}$ & $\mathrm{Y}$ & & \\
\hline \multicolumn{4}{|c|}{$\begin{array}{l}\text { Congruity between methodology and presenting } \\
\text { data }\end{array}$} & Y & $\mathrm{Y}$ & $\mathrm{Y}$ & & \\
\hline \multicolumn{4}{|c|}{ Congruity between methodology and results } & Y & $\mathrm{Y}$ & $\mathrm{Y}$ & & \\
\hline \multirow{2}{*}{\multicolumn{4}{|c|}{$\begin{array}{l}\text { Cultural and theoretical location } \\
\text { Influence of researcher }\end{array}$}} & $\mathrm{N}$ & $\mathrm{U}$ & $\mathrm{U}$ & & $\begin{array}{r}\text { Table } 5 . \\
\text { Critical annraisal }\end{array}$ \\
\hline & \multirow{2}{*}{\multicolumn{3}{|c|}{$\begin{array}{l}\text { Influence of researcher } \\
\text { Particinants' vice renresented }\end{array}$}} & $\mathrm{U}$ & $\mathrm{U}$ & $\mathrm{Y}$ & & Critical appraisal \\
\hline \multirow{2}{*}{\multicolumn{2}{|c|}{$\begin{array}{l}\text { Participants voice represented } \\
\text { Ethical approval }\end{array}$}} & & & $\mathrm{Y}$ & Y & $\mathrm{Y}$ & & $\begin{array}{l}\text { results of eligible } \\
\text { qualitative studies in }\end{array}$ \\
\hline & & & & $\mathrm{Y}$ & $\mathrm{Y}$ & $\mathrm{Y}$ & & svstematic review of \\
\hline \multicolumn{4}{|c|}{ Conclusion } & $\mathrm{Y}$ & $\mathrm{Y}$ & $\mathrm{Y}$ & & systenline text-based \\
\hline \multirow{2}{*}{\multicolumn{8}{|c|}{ Note(s): Abbreviations: $\mathrm{Y}=\mathrm{Yes} ; \mathrm{N}=\mathrm{No} ; \mathrm{U}=$ Unclear }} & intervention and eating \\
\hline & & & & & & & & disorder management \\
\hline
\end{tabular}

reducing the need for healthcare personnel manpower enabled more frequent follow-up. However, participants also criticized interventions delivered via text messages as being too standardized and impersonal [50]. 
JHR

36,6

In terms of the feasibility and acceptability of TTIs, the current literature generally shows that retention rate and adherence rate were high and participant feedback was positive [26, 66-68]. However, some participants and therapists in reviewed studies preferred to face-toface consultations. In contrast to texting interventions, email or online chat (chat group, webpage-based chat) interventions involved a human therapist on the other end. Therefore, chat interventions were able to conduct more complex and complete therapeutic process. Also, the responses were more personalized and appropriate. These modalities gave participants opportunities to discuss their situations and concerns [47, 50]. But this type of intervention was less frequent than text-message interventions.

There are some limitations in our review that are worth noting. The quality of these studies varied. First, $66 \%(n=10)$ of the studies were non-randomized studies (e.g. single-arm trial, case report) with small samples. Moreover, one-fourth $(n=4)$ of the studies did not use validated instruments or indicate the instrument. Also, half $(n=7)$ of the studies used TTIs as an adjunct to face-to-face treatment or bigger online treatment. For these studies, it is hard to conclude that the changes in outcome were due to TTIs, those results therefore should be interpreted cautiously.

\section{Conclusion}

Overall, our review found that TTIs generally had positive results on the management of EDs. TTIs including email, text-messaging, webpage and online chat room, are viable ways to enhance or deliver multiple levels of treatment for EDs. They help reduce ED-related symptoms, comorbid depression and anxiety, improve body satisfaction and contact between clients and therapists. However, due variability in quality of the reviewed studies, our conclusions should be interpreted with some caution. In the future, more rigorously designed studies with larger samples are required to evaluate the effectiveness of TTIs for EDs.

Conflict of Interest: None

\section{References}

1. American Psychiatric Association. Diagnostic and statistical manual of mental disorders (DSM5®). Washington, DC: American Psychiatric Association; 2013.

2. Keski-Rahkonen A, Mustelin L. Epidemiology of eating disorders in Europe: prevalence, incidence, comorbidity, course, consequences, and risk factors. Curr Opin Psychiatry. 2016; 29(6): 340-5. doi: 10.1097/YCO.0000000000000278.

3. Galmiche M, Déchelotte P, Lambert G, Tavolacci MP. Prevalence of eating disorders over the 2000-2018 period: a systematic literature review. Am J Clin Nutr. 2019; 109(5): 1402-13. doi: 10. 1093/ajcn/nqy342.

4. Harrop EN, Marlatt GA. The comorbidity of substance use disorders and eating disorders in women: prevalence, etiology, and treatment. Addict Behav. 2010; 35(5): 392-8. doi: 10.1016/j. addbeh.2009.12.016.

5. Striegel-Moore RH, DeBar L, Wilson GT, Dickerson J, Rosselli F, Perrin N, et al. Health services use in eating disorders. Psychol Med. 2008; 38(10): 1465-74. doi: 10.1017/s0033291707001833.

6. Stuhldreher N, Konnopka A, Wild B, Herzog W, Zipfel S, Löwe B, et al. Cost-of-illness studies and cost-effectiveness analyses in eating disorders: a systematic review. Int J Eat Disord. 2012; 45(4): 476-91. doi: 10.1002/eat.20977.

7. National Eating Disorders Collaboration [NEDC]. Eating disorders prevention, treatment \& management: an evidence review. Crows Nest, NSW: NEDC; 2010.

8. National Eating Disorders Collaboration [NEDC]. Common health consequences of eating disorders. Crows Nest, NSW: NEDC; 2018. 
9. Bahji A, Mazhar MN, Hudson CC, Nadkarni P, MacNeil BA, Hawken E. Prevalence of substance use disorder comorbidity among individuals with eating disorders: a systematic review and metaanalysis. Psychiatry Res. 2019; 273: 58-66. doi: 10.1016/j.psychres.2019.01.007.

10. Carter JC, Mercer-Lynn KB, Norwood SJ, Bewell-Weiss CV, Crosby RD, Woodside DB, et al. A prospective study of predictors of relapse in anorexia nervosa: implications for relapse prevention. Psychiatry Res. 2012; 200(2-3): 518-23. doi: 10.1016/j.psychres.2012.04.037.

11. Olmsted MP, Kaplan AS, Rockert W. Defining remission and relapse in bulimia nervosa. Int J Eat Disord. 2005; 38(1): 1-6. doi: 10.1002/eat.20144.

12. McFarlane T, Olmsted MP, Trottier K. Timing and prediction of relapse in a transdiagnostic eating disorder sample. Int J Eat Disord. 2008; 41(7): 587-93. doi: 10.1002/eat.20550.

13. Arcelus J, Mitchell AJ, Wales J, Nielsen S. Mortality rates in patients with anorexia nervosa and other eating disorders. A meta-analysis of 36 studies. Arch Gen Psychiatry. 2011; 68(7): 724-31. doi: 10.1001/archgenpsychiatry.2011.74.

14. Bohrer BK, Carroll IA, Forbush KT, Chen PY. Treatment seeking for eating disorders: results from a nationally representative study. Int J Eat Disord. 2017; 50(12): 1341-9. doi: 10.1002/eat.22785.

15. Evans EJ, Hay PJ, Mond J, Paxton SJ, Quirk F, Rodgers B, et al. Barriers to help-seeking in young women with eating disorders: a qualitative exploration in a longitudinal community survey. Eat Disord. 2011; 19(3): 270-85. doi: 10.1080/10640266.2011.566152.

16. Ali K, Farrer L, Fassnacht DB, Gulliver A, Bauer S, Griffiths KM. Perceived barriers and facilitators towards help-seeking for eating disorders: a systematic review. Int J Eat Disord. 2017; 50(1): 9-21. doi: 10.1002/eat.22598.

17. Backhaus A, Agha Z, Maglione ML, Repp A, Ross B, Zuest D, et al. Videoconferencing psychotherapy: a systematic review. Psychol Serv. 2012; 9(2): 111-31. doi: 10.1037/a0027924.

18. Francis K, Boyd C, Aisbett D, Newnham K, Newnham K. Rural adolescents' attitudes to seeking help for mental health problems. Youth Studies Australia. 2006; 25(4): 42-9.

19. Lawes-Wickwar S, McBain H, Mulligan K. Application and effectiveness of telehealth to support severe mental illness management: systematic review. JMIR Ment Health. 2018; 5(4): e62. doi: 10. 2196/mental.8816.

20. Myers TC, Swan-Kremeier L, Wonderlich S, Lancaster K, Mitchell JE. The use of alternative delivery systems and new technologies in the treatment of patients with eating disorders. Int J Eat Disord. 2004; 36(2): 123-43. doi: 10.1002/eat.20032.

21. Bauer S, Moessner M. Harnessing the power of technology for the treatment and prevention of eating disorders. Int J Eat Disord. 2013; 46(5): 508-15. doi: 10.1002/eat.22109.

22. Barakat S, Maguire S, Smith KE, Mason TB, Crosby RD, Touyz S. Evaluating the role of digital intervention design in treatment outcomes and adherence to eTherapy programs for eating disorders: a systematic review and meta-analysis. Int J Eat Disord. 2019; 52(10): 1077-94. doi: 10.1002/eat.23131.

23. Simpson S, Knox J, Mitchell D, Ferguson J, Brebner J, Brebner E. A multidisciplinary approach to the treatment of eating disorders via videoconferencing in north-east Scotland. J Telemed Telecare. 2003; 9(Suppl.1): 37-8. doi: 10.1258/135763303322196286.

24. Simpson S, Bell L, Knox J, Mitchell D. Therapy via videoconferencing: a route to client empowerment? Clin Psychol Psychother. 2005; 12(2): 156-65. doi: 10.1002/cpp.436.

25. Marrone S, Mitchell JE, Crosby R, Wonderlich S, Jollie-Trottier T. Predictors of response to cognitive behavioral treatment for bulimia nervosa delivered via telemedicine versus face-to-face. Int J Eat Disord. 2009; 42(3): 222-7. doi: 10.1002/eat.20603.

26. Shingleton RM, Richards LK, Thompson-Brenner H. Using technology within the treatment of eating disorders: a clinical practice review. Psychotherapy (Chic). 2013; 50(4): 576-82. doi: 10.1037/a0031815.

27. Mitchell JE, Crosby RD, Wonderlich SA, Crow S, Lancaster K, Simonich H, et al. A randomized trial comparing the efficacy of cognitive-behavioral therapy for bulimia nervosa delivered via telemedicine versus face-to-face. Behav Res Ther. 2008; 46(5): 581-92. doi: 10.1016/j.brat.2008.02.004.
Text-based telehealth in $\mathrm{ED}$

management 
JHR

36,6

1162

28. Schlegl S, Bürger C, Schmidt L, Herbst N, Voderholzer U. The potential of technology-based psychological interventions for anorexia and bulimia nervosa: a systematic review and recommendations for future research. J Med Internet Res. 2015; 17(3): e85. doi: 10.2196/ jmir.3554.

29. Bakke B, Mitchell J, Wonderlich S, Erickson R. Administering cognitive-behavioral therapy for bulimia nervosa via telemedicine in rural settings. Int J Eat Disord. 2001; 30(4): 454-7. doi: 10.1002/ eat.1107.

30. Simpson S. Psychotherapy via videoconferencing: a review. Br J Guid Counc. 2009; 37(3): 271-86. doi: 10.1080/03069880902957007.

31. Gibson K, Kakepetum-Schultz T, Coulson H, O'Donnell S. Telemental health with remote and rural first nations: advantages, disadvantages, and ways forward. In: National Aboriginal Health Organization (NAHO) Conference; 2009 November 24-27; Ottawa, Canada.

32. Allen M, Sargeant J, Mann K, Fleming M, Premi J. Videoconferencing for practice-based smallgroup continuing medical education: feasibility, acceptability, effectiveness, and cost. J Contin Educ Health Prof. 2003; 23(1): 38-47. doi: 10.1002/chp.1340230107.

33. Vermont State Highway Safety Office. Worldwide texting statistics. [cited 2021 Feb]. Available at: https:/ghsp.vermont.gov/sites/ghsp/files/documents/Worldwide\%20Texting \%20Statistics.pdf.

34. Mahmud N, Rodriguez J, Nesbit J. A text message-based intervention to bridge the healthcare communication gap in the rural developing world. Technol Health Care. 2010; 18(2): 137-44. doi: 10. 3233/thc-2010-0576.

35. Senanayake B, Wickramasinghe SI, Chatfield MD, Hansen J, Edirippulige S, Smith AC. Effectiveness of text messaging interventions for the management of depression: a systematic review and meta-analysis. J Telemed Telecare. 2019; 25(9): 513-23. doi: 10.1177/1357633x19875852.

36. Hoermann S, McCabe KL, Milne DN, Calvo RA. Application of synchronous text-based dialogue systems in mental health interventions: systematic review. J Med Internet Res. 2017; 19(8): e267. doi: 10.2196/jmir.7023.

37. Voruganti T, Grunfeld E, Makuwaza T, Bender JL. Web-based tools for text-based patientprovider communication in chronic conditions: scoping review. J Med Internet Res. 2017; 19(10): e366. doi: 10.2196/jmir.7987.

38. Herbert L, Owen V, Pascarella L, Streisand R. Text message interventions for children and adolescents with type 1 diabetes: a systematic review. Diabetes Technol Ther. 2013; 15(5): 362-70. doi: 10.1089/dia.2012.0291.

39. Scott-Sheldon LA, Lantini R, Jennings EG, Thind H, Rosen RK, Salmoirago-Blotcher E, et al. Text messaging-based interventions for smoking cessation: a systematic review and meta-analysis. JMIR Mhealth Uhealth. 2016; 4(2): e49. doi: 10.2196/mhealth.5436.

40. Keating SR, McCurry MK. Systematic review of text messaging as an intervention for adolescent obesity. J Am Assoc Nurse Pract. 2015; 27(12): 714-20. doi: 10.1002/2327-6924.12264.

41. Ali K, Farrer L, Gulliver A, Griffiths KM. Online peer-to-peer support for young people with mental health problems: a systematic review. JMIR Ment Health. 2015; 2(2): e19. doi: 10.2196/ mental.4418.

42. Moher D, Liberati A, Tetzlaff J, A.ltman DG. Preferred reporting items for systematic reviews and meta-analyses: the PRISMA statement. Ann Intern Med. 2009; 151(4): 264-9, w64. doi: 10.7326/ 0003-4819-151-4-200908180-00135.

43. Lockwood C, Munn Z, Porritt K. Qualitative research synthesis: methodological guidance for systematic reviewers utilizing meta-aggregation. Int J Evid Based Healthc. 2015; 13(3): 179-87. doi: 10.1097/xeb.0000000000000062.

44. Joanna Briggs Institute. The Joanna Briggs Institute critical appraisal tools for use in JBI systematic reviews: checklist for randomized controlled trials. [updated 2017; cited $2021 \mathrm{Feb}$ ]. Available at: https://joannabriggs.org/sites/default/files/2019-05/JBI_RCTs_Appraisal_tool2017_ 0.pdf. 
45. Joanna Briggs Institute. The Joanna Briggs Institute Critical Appraisal tools for use in JBI Systematic Reviews: checklist for quasi-experimental studies (non-randomized experimental studies). [updated 2017; cited $2021 \mathrm{Feb}$. Available at: https:/joannabriggs.org/sites/default/files/ 2019-05/JBI_Quasi-Experimental_Appraisal_Tool2017_0.pdf.

46. Robinson P, Serfaty M. Getting better byte by byte: a pilot randomised controlled trial of email therapy for bulimia nervosa and binge eating disorder. Eur Eat Disord Rev. 2008; 16(2): 84-93. doi: 10.1002/erv.818.

47. Wagner B, Nagl M, Dölemeyer R, Klinitzke G, Steinig J, Hilbert A, et al. Randomized controlled trial of an internet-based cognitive-behavioral treatment program for binge-eating disorder. Behav Ther. 2016; 47(4): 500-14. doi: 10.1016/j.beth.2016.01.006.

48. Zerwas SC, Watson HJ, Hofmeier SM, Levine MD, Hamer RM, Crosby RD, et al. CBT4BN: a randomized controlled trial of online chat and face-to-face group therapy for bulimia nervosa. Psychother Psychosom. 2017; 86(1): 47-53. doi: 10.1159/000449025.

49. Robinson PH, Serfaty MA. The use of e-mail in the identification of bulimia nervosa and its treatment. Eur Eat Disord Rev. 2001; 9(3): 182-93. doi: 10.1002/erv.411.

50. ter Huurne ED, Postel MG, de Haan HA, Drossaert CH, DeJong CA. Web-based treatment program using intensive therapeutic contact for patients with eating disorders: before-after study. J Med Internet Res. 2013; 15(2): e12. doi: 10.2196/jmir.2211.

51. Shingleton RM, Pratt EM, Gorman B, Barlow DH, Palfai TP, Thompson-Brenner H. Motivational text message intervention for eating disorders: a single-case alternating treatment design using ecological momentary assessment. Behav Ther. 2016; 47(3): 325-38. doi: 10.1016/j.beth.2016.01.005.

52. Yager J. E-mail as a therapeutic adjunct in the outpatient treatment of anorexia nervosa: illustrative case material and discussion of the issues. Int J Eat Disord. 2001; 29(2): 125-38.

53. Yager J. E-mail therapy for anorexia nervosa: prospects and limitations. Eur Eat Disord Rev. 2003; 11(3): 198-209. doi: 10.1002/erv.526.

54. Moessner M, Bauer S. Online counselling for eating disorders: reaching an underserved population? J Ment Health. 2012; 21(4): 336-45. doi: 10.3109/09638237.2011.643512.

55. Bauer S, Percevic R, Okon E, Meermann R, Kordy H. Use of text messaging in the aftercare of patients with bulimia nervosa. Eur Eat Disord Rev. 2003; 11(3): 279-90. doi: 10.1002/erv.521.

56. Bauer S, Okon E, Meermann R, Kordy H. Technology-enhanced maintenance of treatment gains in eating disorders: efficacy of an intervention delivered via text messaging. J Consult Clin Psychol. 2012; 80(4): 700-6. doi: 10.1037/a0028030.

57. Shapiro JR, Bauer S, Andrews E, Pisetsky E, Bulik-Sullivan B, Hamer RM, et al. Mobile therapy: use of text-messaging in the treatment of bulimia nervosa. Int J Eat Disord. 2010; 43(6): 513-9. doi: 10.1002/eat.20744.

58. Robinson S, Perkins S, Bauer S, Hammond N, Treasure J, Schmidt U. Aftercare intervention through text messaging in the treatment of bulimia nervosa-feasibility pilot. Int J Eat Disord. 2006; 39(8): 633-8. doi: 10.1002/eat.20272.

59. Gulec H, Moessner M, Mezei A, Kohls E, Túry F, Bauer S. Internet-based maintenance treatment for patients with eating disorders. Prof Psychol Res Pr. 2011; 42(6): 479-86. doi: 10. 1037/a0025806.

60. Gulec H, Moessner M, Túry F, Fiedler P, Mezei A, Bauer S. A randomized controlled trial of an internet-based posttreatment care for patients with eating disorders. Telemed J E Health. 2014; 20(10): 916-22. doi: 10.1089/tmj.2013.0353.

61. Ruwaard J, Lange A, Broeksteeg J, Renteria-Agirre A, Schrieken B, Dolan CV, et al. Online cognitive-behavioural treatment of bulimic symptoms: a randomized controlled trial. Clin Psychol Psychother. 2013; 20(4): 308-18. doi: 10.1002/cpp.1767.

62. Carrard I, Crépin C, Rouget P, Lam T, Golay A, Van der Linden M. Randomised controlled trial of a guided self-help treatment on the Internet for binge eating disorder. Behav Res Ther. 2011; 49(8): 482-91. doi: 10.1016/j.brat.2011.05.004. 
JHR

36,6
63. Popelka J, Quick V, Murray P, Olfert M. The use of technology in eating disorder treatment programs (1020.4). FASEB J. 2014; 28(S1): 1020.4. doi: 10.1096/fasebj.28.1_supplement.1020.4.

64. Linardon J, Wade TD, de la Piedad Garcia X, Brennan L. The efficacy of cognitive-behavioral therapy for eating disorders: a systematic review and meta-analysis. J Consult Clin Psychol. 2017; 85(11): 1080-94. doi: 10.1037/ccp0000245.

65. Hennemann S, Farnsteiner S, Sander L. Internet- and mobile-based aftercare and relapse prevention in mental disorders: a systematic review and recommendations for future research. Internet Interv. 2018; 14: 1-17. doi: 10.1016/j.invent.2018.09.001.

66. Berrouiguet S, Baca-García E, Brandt S, Walter M, Courtet P. Fundamentals for Future MobileHealth (mHealth): a systematic review of mobile phone and web-based text messaging in mental health. J Med Internet Res. 2016; 18(6): e135. doi: 10.2196/jmir.5066.

67. Wei J, Hollin I, Kachnowski S. A review of the use of mobile phone text messaging in clinical and healthy behaviour interventions. J Telemed Telecare. 2011; 17(1): 41-8. doi: 10.1258/jtt.2010.100322.

68. Shaw R, Bosworth H. Short message service (SMS) text messaging as an intervention medium for weight loss: a literature review. Health Inform J. 2012; 18(4): 235-50. doi: 10.1177/ 1460458212442422 .

\section{Appendix 1 \\ Search terms \\ Results:}

\section{PsycINFO}

Abstract: telemedicine OR mHealth OR "mobile health" OR "text message" OR text-messaging OR textmessages OR text-based OR email OR e-mail OR chatroom OR "chat room" OR forum OR "discussion board" OR "message board" AND Abstract: "eating disorder" OR "eating disorders" OR bulimi* OR anorexi* OR binge eat* OR EDNOS AND Year: 2000 To 9999

$$
164
$$

\section{PubMed}

(telemedicine[Title/Abstract] OR mHealth[Title/Abstract] OR "mobile health"[Title/Abstract] OR "text message"[Title/Abstract] OR text-messaging[Title/Abstract] OR text-messages[Title/Abstract] OR textbased[Title/Abstract] OR email[Title/Abstract] OR e-mail[Title/Abstract] OR chatroom[Title/Abstract] OR "chat room"[Title/Abstract] OR forum[Title/Abstract] OR “discussion board"[Title/Abstract] OR "message board"[Title/Abstract]) AND ("eating disorder"[Title/Abstract] OR "eating disorders"[Title/ Abstract] OR bulimi*[Title/Abstract] OR anorexi*[Title/Abstract] OR binge eat*[Title/Abstract] OR EDNOS[Title/Abstract]) Filters applied: from 2000/1/1 - 3000/12/12.

$$
177
$$

\section{Embase}

("eating disorder":ab,ti OR “eating disorders":ab,ti OR bulimi*:ab,ti OR anorexi*:ab,ti OR "binge eat*”:ab,ti OR ednos:ab,ti) AND (telemedicine:ab,ti OR mhealth:ab,ti OR "mobile health":ab,ti OR "text message":ab,ti OR “text messaging”:ab,ti OR “text messages”:ab,ti OR “text based”:ab,ti OR email:ab,ti OR “e mail”:ab,ti OR chatroom:ab,ti OR “chat room”:ab,ti OR forum:ab,ti OR “discussion board":ab,ti OR "message board”:ab,ti) AND [2000-2021]/py

$$
207
$$

\section{CINAHL}

$\mathrm{AB}$ ("eating disorder" OR "eating disorders" OR bulimi* OR anorexi* OR binge eat* OR EDNOS) AND $\mathrm{AB}$ (telemedicine OR mHealth OR "mobile health" OR "text message" OR text-messaging OR text- 
messages OR text-based OR email OR e-mail OR chatroom OR "chat room" OR forum OR "discussion board” OR "message board”) Limiters - Published Date: 20000101-20210631 Expanders - Apply equivalent subjects Search modes - Boolean/Phrase

105

Corresponding author

Xiaoyun Zhou can be contacted at: xiaoyun.zhou1@uqconnect.edu.au
Text-based telehealth in

$\mathrm{ED}$

management

1165

For instructions on how to order reprints of this article, please visit our website:

www.emeraldgrouppublishing.com/licensing/reprints.htm

Or contact us for further details: permissions@emeraldinsight.com 